\title{
SEM of Soluble Polysaccharides Extracted from the Cell Walls of the Marine Brown Alga Padina gymnospora
}

\author{
L.R. Andrade*, L.T. Salgado*, M. Farina*, and G.M. Amado Filho** \\ * Laboratório de Biomineralização, Instituto de Ciências Biomédicas, UFRJ, Brasil, 21941-590. \\ ** Prog. Zona Costeira, Inst. de Pesquisas Jardim Botânico do Rio de Janeiro, Brasil, 22460-030.
}

The cell walls of marine algae have predominantly negatively charged polysaccharides, while land plants have neutral ones. The brown algae cell walls are formed by a fibrous skeleton of cellulose embedded in a mucilaginous matrix composed by acid polysaccharides. These polysaccharides are commonly known as fucans, which contain sulfydril groups and alginates which contain carboxylic groups. These compounds are responsible, principally, to wall stability and osmotic balance and it was suggested that these polysaccharides are the main responsible for heavy metals binding and precipitation by the cell walls [1]. In this work, we describe the ultrastructure of the fractioned alginates and fucans of $P$. gymnospora by using SEM and EDXA.

Samples of $P$. gymnospora were collected in Angra dos Reis (near Rio de Janeiro city), washed in distilled water and dried at $50{ }^{\circ} \mathrm{C}$. The polysaccharides were extracted from biomass with ultra-pure water for $24 \mathrm{~h}$ under agitation. The solution was centrifuged, the polysaccharides precipitated with ethanol and freeze-dried. The powder of polysaccharide fractions (total, alginates and fucans) were deposited on a carbon tape on copper stubs, sputtered with gold (Balzers/Union FL-9496), and observed in the Field Emission SEM Jeol $6340 \mathrm{~F}$, operated at $10 \mathrm{kV}$. X-ray microanalysis was done in fractions to determine their elemental composition. A Transmission Electron Microscope Jeol 1200 EX equipped with a Noran-Voyager analytical system was used.

Field Emission SEM of the total polysaccharides presented self-assembled structures, forming different lamellar or trabecular patterns (figure 1 and 2). FESEM of fucans showed numerous cubic forms, linked by a specific face (figure 3 ). The particle sizes were in a range of $4-20 \mu \mathrm{m}$. Sulfur was detected as the characteristic element due to the presence of sulfate groups (figure 4). FESEM of alginates revealed a sponge-like structure with pores with thin walls or a sheet-like appearance (figure 5). Ca was determined as the characteristic element, bound as calcium alginate (figure 6).

Our observations showed the specific structure and composition of fucans and alginates by FESEM and X-ray microanalysis. The general architecture of cell walls in the alga is maintained by the selfassembly of cellulose and alginate chains, and it was suggested that sulfated fucans play a key role in cross-linking cellulose and alginates [2]. Recently, it was proposed that actin filaments are involved in the orientation of the cellulose microfibrils [3]. Here we reported for the first time the ultrastructure of matrix polysaccharides isolated from a brown alga species.

\section{References}

[1] L.R. Andrade et al., Phycologia 40 (2002) 39.

[2] B. Kloareg and R. Quatrano, Oceanogr. Mar. Biol. Annu. Rev. 26 (1988) 259.

[3] C.I. Katsaros et al., Phycologia 41 (2002) 178.

[4] This research was supported by FAPERJ and CNPq. 

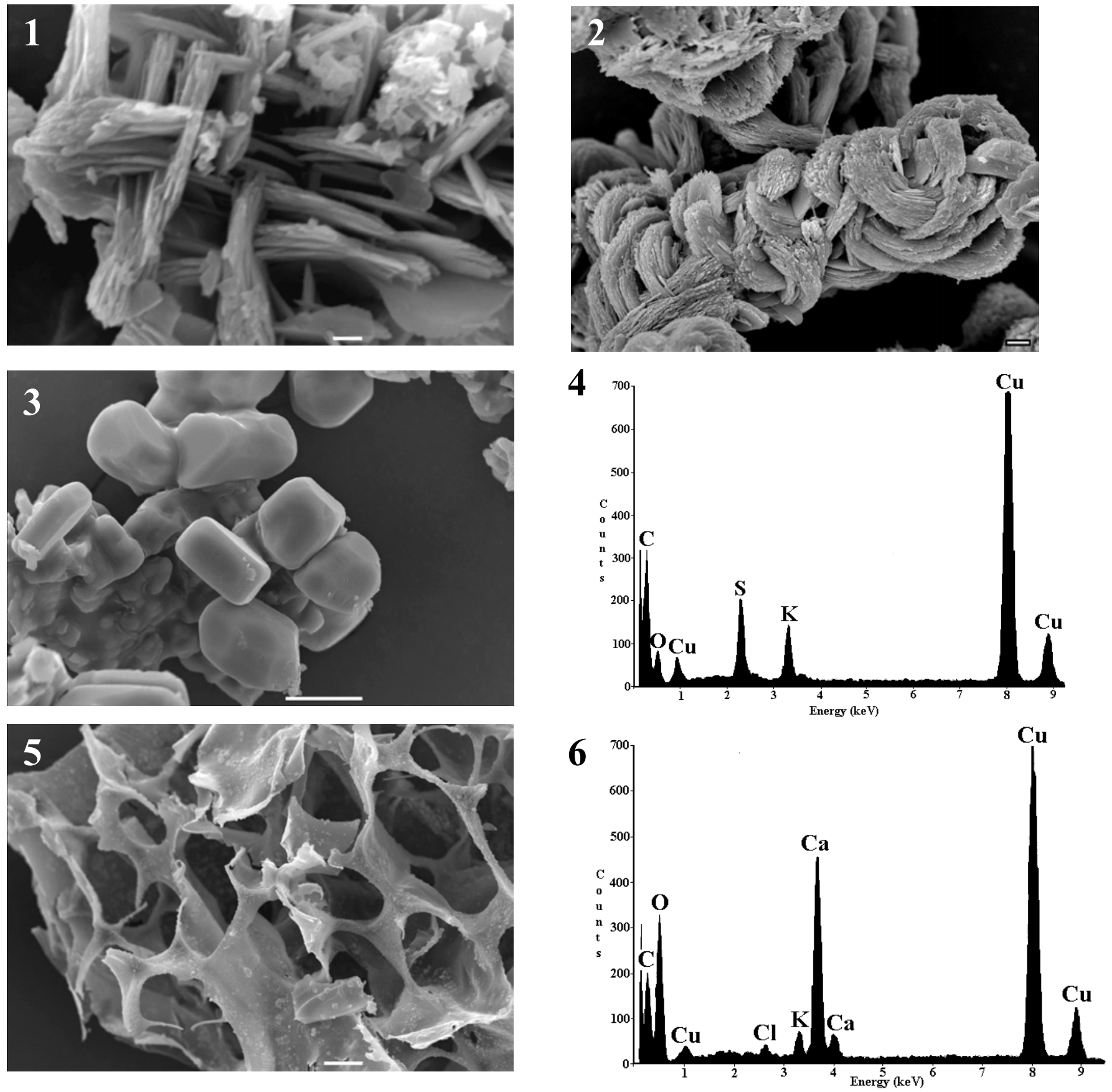

Figure 1: SEM of the total polysaccharides showing the lamellar pattern. Bar $=1 \mu \mathrm{m}$

Figure 2: FESEM of the total polysaccharides showing a particular organization of the lamelae. $\operatorname{Bar}=10 \mu \mathrm{m}$

Figure 3: FESEM of the fucan fraction showing the cuboid particles. Bar $=5 \mu \mathrm{m}$ Figure 4: EDXA spectrum of the fucans fraction. Note the presence of $\mathrm{S}$.

Figure 5: FESEM of the alginates showing the sponge like structure. Bar $=10 \mu \mathrm{m}$ Figure 6: EDXA spectrum of the alginate fraction. Note the presence of $\mathrm{Ca}$. 